\section{Комплексные исследования процесса производства щепы}

\author{
С. Б. Васильев ${ }^{1}$ \\ Петрозаводский государственный университет
}

\section{АННОТАЦИЯ}

В статье приводится краткое описание методики и результаты исследований процессов измельчения древесины, сортирования и доизмельчения полученных древесных частиц.

Ключевые слова: щела, машина рубительная, сортировка щепы, фракционный состав, дезинтеграmop.

\section{SUMMARY}

Chipping, chips screening and rechipping processes complex investigation methods and results are under discussion.

Keywords: chips, chipper, chips screen, rechipper, chips classification.

\section{СОСТОЯНИЕ ВОПРОСА}

Решением проблемы комплексного использования биомассы дерева, включая вопросы переработки вторичных ресурсов лесозаготовок и лесопиления на технологическую щепу, с давних пор занимался ряд исследователей России [1-4]. Однако полученных ими данных не достаточно для повышения эффективности комплексных процессов переработки различных видов биомассы дерева и вторичных ресурсов различных производств на технологическую щепу. Процесс производства щепы не рассматривается как комплекс, состоящий из операций и оборудования для измельчения, сортирования и доизмельчения полученного продукта.

На основании анализа работ предшественников, посвященных рассматриваемой проблеме, автором были сформулированы основные направления научного поиска и задачи исследования:

- провести исследование процесса переработки различных видов древесного сырья в рубительной машине;

- провести исследование процесса сортирования различных видов щепы на гирационных сортировках;

- провести исследование процесса доизмельчения крупной фракции щепы;

- разработать рекомендации по формированию технологических потоков, обеспечивающих переработку всех видов биомассы дерева на щепу с минимальными потерями.

\footnotetext{
${ }^{1}$ Автор - профессор кафедры технологии и оборудования лесного комплекса

(C) С. Б. Васильев, 2003
}

\section{МЕТОДИКА ЭКСПЕРИМЕНТАЛЬНЫХ ИССЛЕДОВАНИЙ}

Изучение процесса переработки различных видов древесного сырья в рубительной машине включало в себя исследование влияния формы рабочей поверхности диска и заточки ножей, коэффициента непрерывности и скорости резания при верхнем и горизонтальном способах выброса на фракционный состав щепы, а также исследование горизонтального выброса щепы при наклонной подаче древесины к диску. Эти исследования были проведены на экспериментальной установке, созданной на базе дисковой рубительной машины МРНП-30. Диск в зависимости от условий эксперимента оснащался комплектом из 4,8 или 16 ножей и накладок, как с геликоидальной, так и с плоской рабочей поверхностью. Частота вращения диска при исследованиях менялась от 100 до 1000 мин. ${ }^{-1}$. Непрерывность резания моделировалась путем изменения сочетания количества ножей на диске и диаметра перерабатываемой древесины.

В качестве критерия для оценки влияния параметров и направлений оптимизации их значений в работе принята доля потерь. Она определялась как сумма мелкой фракции, отсева и доли крупной фракции, которая превращается в мелкую и отсев при доизмельчении. Фракционирование щепы осуществлялось на анализаторе АЛГ-М.

Исследования процесса сортирования щепы осуществлялись с использованием экспериментальной установки, состоящей из гирационной сортировки с переменными характеристиками режимов сортирования щепы; дозатора, предназначенного для изменения количества подаваемой щепы; бункера несортированной щепы объемом $3 \mathrm{~m}^{3}$. В сортировке могут устанавливаться одновременно два яруса сит, угол наклона которых регулируется в диапазоне $2-11^{\circ}$.

Диапазоны варьируемых в ходе экспериментальных исследований факторов: амплитуда колебаний сит 20-80 мм; частота колебаний сит - $1,7 \ldots .5,9$ Гц, толщина сортируемого слоя - 20-80 мм, длина сит 0,55-1,5 м. Исследовались сита: с квадратными отверстиями размером $60 \times 60,39 \times 39,8 \times 8,6 \times 6$ мм; с круглыми отверстиями диаметром $60,50,22,18,14,10,8$ мм; с ромбическими отверстиями с размером большей диагонали 8 мм. В каждом опыте фиксировались: время сортирования с точностью до 1 с; объемы надрешетного и подрешетного продуктов с точностью 0,001 нас. м ${ }^{3}$; фракционный состав надрешетного и подрешетного продуктов с точностью $5 \%$.

Отбор проб и определение фракционного состава осуществлялись в соответствии с ГОСТ 15815-83. Толщина слоя щепы поддерживалась дозирующим устройством.

Экспериментальные исследования процесса доизмельчения крупной фракции щепы проводились на рубительной машине МРБ-5, барабанном дезинтеграторе щепы ДЗН-1 и дисковом дезинтеграторе «Andritz» CHR10-13A шведской фирмы «KONE WOOD». 
В рубительной машине МРБ-5 измельчались крупные отходы сортирования щепы, полученной из круглой древесины на дисковой рубительной машине МРНП30 ; из переработанной на щепу деревянной тары. Испытания дезинтеграторов ДЗН-1 и «Andritz» CHR10-13А проводились на отходах сортирования щепы, полученной из круглой древесины на рубительной машине МРН-100-1.

\section{РЕЗУЛЬТАТЫ ИССЛЕДОВАНИЙ}

Исследованиями процесса измельчения биомассы дерева на щепу установлено, что замена плоской рабочей поверхности диска и прямой заточки ножей на геликоидальные уменьшает долю потерь на 10-20\%. Увеличение коэффициента непрерывности резания приводит к снижению доли потерь в щепе за счет уменьшения в ней долей крупной и мелкой фракций и отсева. При изменении значений этого коэффициента от 0,15 до 0,60 интенсивность процесса резко возрастает, а дальнейшее увеличение коэффициента на содержании потерь сказывается незначительно.

В результате установлено, что доля мелкой фракции и отсева в щепе с увеличением скорости резания возрастает, доля крупной - снижается. В целом доля потерь при производстве щепы с ростом скорости резания возрастает (рис.)

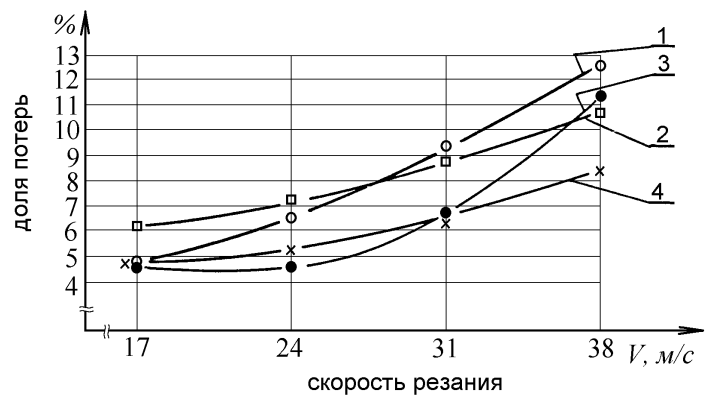

Рис. Зависимости доли потерь от скорости резания при: 1 - геликоидальной форме поверхности и верхнем выбросе; 2 - плоской форме поверхности и верхнем выбросе; 3 - геликоидальной форме поверхности и горизонтальном выбросе; 4 - плоской форме поверхности и горизонтальном выбросе

Экспериментальные исследования показали, что при горизонтальном способе выброса щепы и коэффициенте непрерывности резания больше единицы оптимальной является скорость резания 24 м/с. При верхнем способе выброса наименьшие значения доли потерь получены при скорости резания 17 м/с. Дальнейшее уменьшение скорости резания невозможно, так как прекращается выброс щепы из кожуха рубительной машины.

В результате обработки экспериментальных данных получены уравнения регрессии, позволяющие определять долю потерь в щепе в зависимости от скорости резания и коэффициента непрерывности:

$$
\begin{aligned}
& \Pi_{в}=6,532-2,417 k+0,005 v^{2}+ \\
& +0,777 k^{2}-0,019 v k, \\
& \Pi_{1}=e^{0,02 v_{v+0,961}}, \\
& \Pi_{2}=16,741-0,114 v-52,382 k+ \\
& +0,006 v^{2}+53,981 k^{2}+0,013 v k,
\end{aligned}
$$

где $\Pi_{6}, \Pi_{1}, \Pi_{2}$ - доли потерь соответственно при верхнем способе выброса щепы, при горизонтальном выбросе и коэффициенте непрерывности больше единицы, при горизонтальном выбросе и коэффициенте непрерывности меньше единицы, \%; v - скорость резания, м/с; $k$ - коэффициент непрерывности резания.

Конструктивные параметры по степени их влияния на долю потерь в щепе расположены в следующем порядке: скорость резания (сила влияния - 0,84...0,95); коэффициент непрерывности резания (сила влияния до 0,62 ); форма рабочей поверхности диска и заточки ножей (сила влияния до 0,36).

Исследования в промышленных условиях подтвердили выводы, сделанные по результатам исследования на стенде, и показали хорошую сходимость результатов расчета потерь по формулам (1)-(3) с полученными на практике (разница находилась в пределах $0,8 \ldots 1,4 \%$, что обеспечивает уровень достоверности по t-критерию не ниже 0,95 ).

В ходе исследований процесса сортирования щепы установлены зависимости скорости схода щепы и точности отсева от частоты и амплитуды колебаний сита:

$v=1,5 \cdot 10^{-3} n^{2} r \sin \alpha$,

где $v$ - скорость схода щепы, м/с; $n$ - частота колебаний ситового короба, Гц; $r$ - амплитуда колебаний, м; $\alpha-$ угол наклона сит, ${ }^{\circ}$.

$$
\begin{aligned}
& \varepsilon_{\mathbf{4}^{5+0^{-}}}=\frac{54,5 \boldsymbol{\beta} 9-2,9 d}{62-1,5 \alpha}, \% \text {; } \\
& \varepsilon_{\leftarrow 10+5}=\frac{14,0 \ll, 7 d-12}{28-2,8 \alpha}, \% \text {; } \\
& \varepsilon_{430^{-}}=\boldsymbol{Q}, 35 d-48^{-}, \% \text {; }
\end{aligned}
$$

где $\varepsilon_{\left\{-5+0^{-}\right.}, \varepsilon_{\uparrow 10+5,}, \varepsilon_{430^{-}}-$точности отсева фракций щепы, соответственно остающейся на поддоне анализатора, на сите анализатора с отверстиями диаметром 5 мм, на сите анализатора с отверстиями диаметром 30 мм; $d$ - диаметр отверстий сит сортировки, мм.

Обработка результатов исследований позволила получить уравнения, связывающие показатели точности отсева различных фракций щепы с диаметром отверстий сита, длиной сита и производительностью сортировки, отнесенной к единице ее ширины, которые представлены в табл. 
Исследования, проведенные в промышленных условиях, показали хорошую сходимость результатов расчета по формулам (4)-(7) и приведенных в табл. с полученными на практике (разница находилась в пределах $1,7 \ldots 2,8$ \%, что обеспечивает уровень достоверности по t-критерию не ниже 0,95$)$.

При доизмельчении крупной щепы в дезинтеграторе получена щепа со следующим фракционным составом: фракция (+30) - 12,4\%; фракция $(-30+10)-60,5$ $\%$; фракция $(-10+5)-19,5 \%$, фракция $(-5+0)-7,6$ $\%$. При переработке крупной щепы в дезинтеграторе происходит уменьшение размера частиц по длине, толщине и ширине соответственно в 2,2; 3,2 и 2,2 раза. Содержание в измельченной щепе частиц толще 7 мм составило 4,4 \%, а длиннее 30 мм - $35 \%$. Содержание мелочи и опилок в полученной щепе превышает $27 \%$.

\section{ВЫВОдЫ}

1. По мере убывания степени влияния на долю потерь в щепе конструкционные параметры дисковых рубительных машин располагаются следующим образом: скорость резания, способ выброса щепы, коэффициент непрерывности резания, форма рабочей поверхности диска и заточки ножей.

2. Только при оптимальной скорости резания и коэффициенте непрерывности резания больше единицы использование геликоидальной наладки ротора по сравнению с плоской позволяет на 10-20\% снизить долю потерь.

3. Доизмельчение и сортирование крупной фракции позволяет вовлечь в технологический процесс $60 \%$ крупной щепы, снизив общий объем потерь на 2,3\%.
4. Рекомендуются следующие параметры гирационных сортировкок: амплитуда колебаний сит - 40 мм, угол наклона сит $-5 \ldots 8^{\circ}$, частота колебаний $2,5 \ldots 3,7$ Гц. Сита сортировок должны иметь круглые отверстия и максимально возможный коэффициент перфорации.

5. Сортировки щепы производительностью 150 и более $\mathrm{m}^{3} /$ ч рекомендуется оснащать не менее чем тремя ярусами сит. В этом случае рекомендуются следующие сита с перфорацией в виде круглых отверстий: для верхнего яруса - с диаметром 45 или 55 мм, для среднего яруса - с диаметром 22 мм, для нижнего яруса - с диаметром 6 или 10 мм в зависимости от фракционного состава щепы, поступающей на сортирование.

\section{СПИСОК ЛИТЕРАТУРЫ}

1. Вальщиков Н. М. Рубительные машины. Л.: Машиностроение, 1970.328 с.

2. Лаутнер Э. М. Основы теории получения технологической щепы и разработка нового поколения дисковых рубительных машин: Науч. доклад на соискание уч. степени докт. техн. наук. СПб.: Изд-во СПбГЛТА, 1996. 52 с.

3. Лицман Э. П. Исследование динамики измельчения древесины // Новое в области автоматизации и интенсификации процессов целлюлозно-бумажного производства: Сб. научн. тр. ВНИИБа, ВНПОбумпрома. Л., 1984. С. 55-62.

4. Коробов В. В., Рушнов Н. П. Переработка низкокачественного древесного сырья: Проблемы безотходной технологии. М.: Экология, 1991. 288 с.

Зависимости для расчета показателей точности*

Таблица

\begin{tabular}{|c|c|}
\hline \multicolumn{2}{|r|}{ Зависимости для расчета показателей точности* } \\
\hline Фракция & Уравнения для расчета точности \\
\hline$(+30)$ & $\varepsilon=\frac{953}{q}+36, \quad \varepsilon=\frac{90}{1+10^{0,44-1,08 L}}$ \\
\hline$(-30+20)$ & $\begin{array}{c}\varepsilon=7,87+0,063 q-1,503 d+0,001 q^{2}-0,008 q d+0,073 d^{2} \\
\varepsilon=\frac{25}{1+10^{0,92-0,84 L}}\end{array}$ \\
\hline$(-20+10)$ & $\begin{array}{l}\varepsilon=8,249-0,035 q+0,867 d+0,002 q^{2}-0,018 q d+0,089 d^{2} \\
\varepsilon=99,86-78,56 L-10,709 d-0,395 L^{2}+5,809 L d+0,28 d^{2}\end{array}$ \\
\hline$(-10+5)$ & $\begin{array}{l}\varepsilon=0,433-0,235 q+2,643 d+0,002 q^{2}-0,003 q d+0,026 d^{2} \\
\varepsilon=8,584-13,937 L+2,849 d-6,141 L^{2}+4,267 L d-0,12 d^{2}\end{array}$ \\
\hline$(-5+0)$ & $\begin{array}{l}\varepsilon=43,316-0,541 q+3,38 d+0,001 q^{2}+0,026 q d-0,087 d^{2} \\
\varepsilon=48,193+54,323 L+6,856 d-10,014 L^{2}+1,52 L d-0,217 d^{2}\end{array}$ \\
\hline
\end{tabular}

